Int. J. Dev. Biol. 57: 885-890 (2013)

doi: $10.1387 / \mathrm{ijdb} .130206 \mathrm{gw}$

\title{
Matrigel supports neural, melanocytic and chondrogenic differentiation of trunk neural crest cells
}

\author{
ANA B. RAMOS-HRYB ${ }^{1}$, MELINE C. DA-COSTA ${ }^{1}$, ANDRÉA G. TRENTIN ${ }^{1,2}$ \\ and GIORDANO W. CALLONI*,1,2 \\ ${ }^{1}$ Programa de Pós-graduação em Biologia Celular e do Desenvolvimento and '2Departamento de Biologia Celular, \\ Embriologia e Genética, CCB, UFSC, Florianópolis, Brazil
}

\begin{abstract}
The neural crest (NC) is composed of highly multipotent precursor cells able to differentiate into both neural and mesenchymal phenotypes. Until now, most studies focusing on NC cell differentiation have been performed with traditional two-dimensional (2D) cell culture systems. However, such culture systems do not reflect the complex three-dimensional (3D) microenvironments of in vivo NC cells. To address this limitation, we have developed a method of Matrigel $^{\mathrm{TM}}$ coating to create 2D and 3D microenvironments in the same culture well. When we performed cultures of trunk neural crest cells (TNCCs) on three different lots of basement membrane matrix (Matrigel ${ }^{\mathrm{TM}}$ ), we observed that all analyzed Matrige ${ }^{\mathrm{TM}}$ lots were equally efficient in allowing the appearance of glial cells, neurons, melanocytes, smooth muscle cells and chondrocytes. We further observed that chondrocytes were found predominantly in the 3D microenvironment, whereas smooth muscle cells were almost exclusively located in the 2D microenvironment. Glial cells were present in both environments, but with broader quantities on the 2D surface. Melanocytes and neurons were equally distributed in both 2D and 3D microenvironments, but with distinct morphologies. It is worth noting the higher frequency of chondrocytes detected in this study using the 3D Matrigel $^{\mathrm{TM}}$ microenvironment compared to previous reports of chondrogenesis obtained from TNCCs on traditional 2D cultures. In conclusion, Matrige ${ }^{\mathrm{TM}}$ represents an attractive scaffold to study NC multipotentiality and differentiation, since it permits the appearance of the major NC phenotypes.
\end{abstract}

KEY WORDS: Matrigel ${ }^{\mathrm{TM}}$, trunk neural crest, cell differentiation, chondrogenesis, 3D microenvironment

\section{Introduction}

The neural crest (NC) represents a highly multipotent cell population that emerges from dorsal neural folds during vertebrate neurulation. Subsequent to epithelial-mesenchymal transition (EMT), $\mathrm{NC}$ cells migrate through specific routes along the vertebrate axial body. During this journey, growth factors and extracellular matrix molecules are essential for the migration and differentiation of NC cells (Le Douarin and Kalcheim 1999).

$\mathrm{NC}$ cells can be divided into two main domains with respect to the embryonic axial level from which they derive: 1) Cephalic Neural Crest (CNC) and 2) Trunk Neural Crest (TNC). Both CNC cells (CNCCs) and TNC cells (TNCCs) give rise to glia and neurons of the peripheral nervous system (PNS), as well as melanocytes and endocrine cells. On the other hand, only CNCCs are able to give rise to mesenchymal cell types in vivo, such as smooth muscle cells, adipocytes, osteocytes and chondrocytes (Le Douarin and Kalcheim
1999). Therefore, CNCCs give rise to most of the connective and skeletal tissues of the neck and head. It is worth noting the in vitro skeletogenic potential of TNCCs when submitted to appropriate conditions (Calloni et al., 2007; McGonnell and Graham 2002).

Currently, it is well accepted that CNCCs are mostly composed of highly multipotent progenitors endowed with both neural and mesenchymal potential (Calloni et al., 2007). On the other hand, the magnitude of TNCC multipotentiality remains an open question, partially resulting from the methodological difficulties encountered in obtaining mesenchymal phenotypes, especially chondrocytes,

\footnotetext{
Abbreviations used in this paper: $\alpha$-SMA, $\alpha$-smooth-muscle actin; $\beta$-tubIII, beta tubulin III; 2D, two-dimensional; 3D, three-dimensional; 10d, ten days; CNC, Cephalic NC; CNCGs, CNG cells; HNK1, Human natural killer-1; NG, Neural Crest; NCGs, NG cells; PNS, Peripheral Nervous System; Shh, Sonic Hedgehog; SMA, smooth muscle cells; SMP, Schwann Myelin Protein; TH, Tyrosine Hydroxylase; TNG, trunk NC; TNGGs, TNG cells.
}

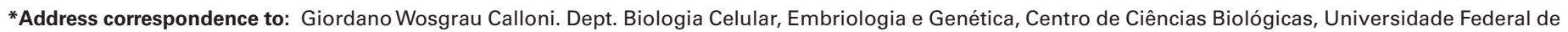

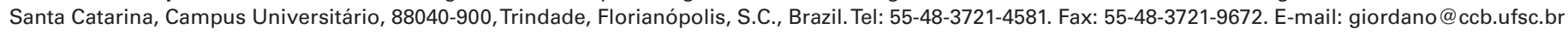


in TNC cultures.

Up to now, NC cell differentiation has been assessed by conventional two-dimensional (2D) culture conditions, such as plastic surfaces coated with extracellular molecules, including fibronectin or collagen, or by mouse embryonic fibroblast (MEF) feeder layers (3T3 fibroblast feeder layers) (Costa-Silva et al., 2009; Ito et al., 1993). Importantly, ЗТ3 fibroblast feeder layers are necessary to detect the full range of NC phenotypes, especially neurons and chondrocytes (Calloni et al., 2007). On the other hand, 3T3 feeder layers are hard to manipulate routinely, limiting the performance of other technical experiments, such as subcloning. For that reason, experiments involving NC self-renewal have been done on collagen-coated surfaces, which restrict the repertoire of NCCs differentiation, especially chondrogenic and neurogenic phenotypes (Bittencourt et al., 2013).

It is currently accepted that three-dimensional (3D) environments are more physiologically related to in vivo tissue complexities than 2D substrates (Birgersdotter et al., 2005). In this sense, Matrigel ${ }^{\mathrm{TM}}$ represents an interesting alternative. Matrigel ${ }^{\mathrm{TM}}$ is a solubilized mixture of proteins and extracellular matrix molecules extracted from basement membrane of a mouse sarcoma (Engelbreth-HolmSwarm), which polymerizes to produce a biologically active gel (Kleinman and Martin 2005). Despite the initial use of Matrigel ${ }^{\mathrm{TM}}$ by the Hay group to study TNCC migration from neural tube explants (Bilozur and Hay 1988), its influence on NCCs differentiation has not been addressed until now. Therefore, it is tempting to assess whether Matrigel can elicit the full range potential of NCCs differentiation.

Here, we developed a system for NCCs culture on both 2D and 3D Matrige ${ }^{\mathrm{TM}}$ microenvironments in the same culture well (Fig. 1). As a result of lot-to-lot variations of Matrigel ${ }^{\mathrm{TM}}$, we evaluated the influence of three Matrigel ${ }^{\mathrm{TM}}$ lots on NCCs differentiation. We observed that Matrigel ${ }^{\mathrm{TM}}$ supports the differentiation of the main
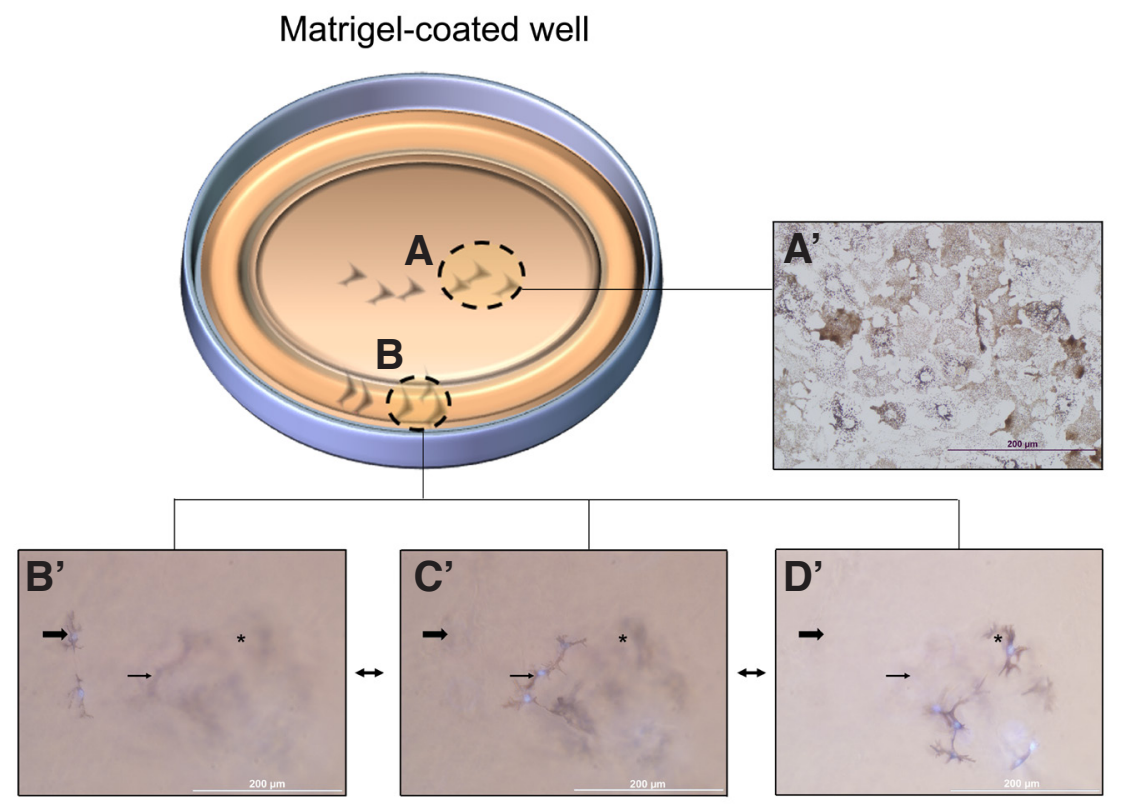

Fig. 1. Methodological approach of (A) 2D and (B) 3D microenvironments to study TNCC differentiation. Primary and secondary cultures of NC cells were performed as described in Materials and Methods. (A) 2D (center) and (B) 3D (border) Matrige/ ${ }^{T M}$ microenvironments of each 96-well plate. Pigmented melanocytes observed after 10d in culture in $2 D\left(\mathbf{A}^{\prime}\right)$ or $3 D$ ( $\left.\mathbf{B}^{\prime}-\mathbf{D}^{\prime}\right)$ Matrige/TM. Arrows in $B^{\prime}-D^{\prime}$ show melanocytes at different $3 D$ levels.
TNC phenotypes, allowing the development of high frequencies of chondrocytes and neurons.

\section{Results}

\section{Matrigel $^{T M}$ supports the differentiation of the main neural crest phenotypes}

In order to address if Matrigel ${ }^{\mathrm{TM}}$ supports the differentiation of the main NC phenotypes, cultures of TNCCs were performed on three different Matrige IM lots, termed I, II and III, separately, or in combination, as I+II+III. NC-derived phenotypes were evaluated after 10 days of secondary cultures.

All tested Matrigel ${ }^{\mathrm{TM}}$ lots allowed the differentiation of glial cells, melanocytes, smooth muscle cells, neurons and chondrocytes (Fig. 2). In $2 \mathrm{D}$ microenviroment the rare cartilage nodules observed assumed a flat morphology (Fig. 2 A-B). Cartilage nodules were observed almost exclusively at the border of the 96-well culture plate, where Matrigel ${ }^{\mathrm{TM}}$ forms a 3D microenvironment (Fig. 2C-D). These cartilage nodules displayed a round morphology, and their forming chondrocytes were loosely attached to each other (Fig. 2 C-D).

Moreover, despite the presence of glial cells at the border of well, most of them were detected in the 2D microenvironment in the center of well. The majority of glial cells co-expressed SMP and HNK1 demonstrating that HNK1 at this stage of NC differentiation is a good marker for glial cells (Fig. $2 \mathrm{E}-\mathrm{H})$. Similarly, smooth muscle cells were found almost exclusively in the 2D microenvironment (Fig. $2 \mathrm{I}$ and K). Both melanocytes and neurons were found on $2 \mathrm{D}$ and $3 \mathrm{D}$ Matrige ${ }^{\mathrm{TM}}$ surfaces (Fig. $2 \mathrm{~J}, \mathrm{~L}, \mathrm{M}$, O). However, glial cells, smooth muscle cells, melanocytes and neurons all exhibited different morphologies, depending on the microenvironment. Specifically, glial cells, smooth muscle cells and melanocytes displayed a flat morphology on the 2D surface (Fig. $2 \mathrm{E}-\mathrm{F}$ and I-J) and a filamentous or elongated morphology, as well as branched cell bodies in the case of melanocytes, in the 3D microenvironment (Fig. 2 G-H, K-L and also Fig. 1 for melanocytes). In the 2D microenvironment, neurons presented long axons arranged in entangled nets (Fig. 2M), whereas an ensheathed filamentous structure was formed in the 3D microenvironment (Fig. 2O). In this later condition, neurons frequently co-expressed beta-tubulin III and HNK1 (data not shown). Rare adrenergic cells were found on 2D microenvironment (Fig. 2N). These cells were preferentially located in the 3D microenvironments, arranged in a cord-like structure (Fig. 2P).

\section{Different Matrigel ${ }^{T M}$ lots support the differentia- tion of neural crest cells in a similar manner}

We also investigated if different Matrige ${ }^{\mathrm{TM}}$ lots could elicit correspondingly different responses in NCC differentiation. To accomplish this, the differentiation of TNCCs was evaluated in three separate lots of Matrigel ${ }^{\mathrm{TM}}$ denoted as I, II and III, or in a combination of lots denoted as $1+11+111$.

Irrespective of lot, 80 to $100 \%$ of the wells contained glial cells, neurons, melanocytes and smooth muscle cells (Fig. 3 ). Almost $80 \%$ of wells 
Fig. 2. Matrigel $\mathrm{T}^{\mathrm{TM}}$ supports differentiation of the main TNCC phenotypes. The phenotypic analysis of TNCCs was performed in 10d cultures on Matrige/ ${ }^{T M}$, as described in Materials and Methods. Despite changes in distribution and morphology, all NC cell types were detected in both 2D (left columns) and 3D (right columns) microenvironments. Cartilage nodules were detected by phase contrast microscopy $(\mathbf{A}, \mathbf{C})$ and chondrocytes were identified by immunoreactivity to chondroitin sulfate (green color in $B, D)$. Cartilage nodules were detected in $2 \mathrm{D}(\mathbf{A}, \mathbf{B})$ and $3 D$ (C-D) microenvironments. In both $2 D(\mathbf{E}, \mathbf{F})$ and $3 D(\mathbf{G}, \mathbf{H})$ microenvironments, glial cells were identified by immunoreactivity to SMP (green color in $E, G$ ) and HNK1 (red color in F,H). Thick arrows in (E-F) show the rare glial cells that were positive for HNK1 and negative for SMP. Smooth muscle cells were identified by immunoreactivity to aSMA in $2 D(\mathbf{I})$ and $3 D(\mathbf{K}) \mathrm{mi}-$ croenvironments. Melanocytes were identified by the presence of melanin pigment in both $2 D$

$(\mathbf{J})$ and $3 D(\mathbf{L})$ microenvironments. Neurons and adrenergic cells were identified in $2 D(\mathbf{M}, \mathbf{N})$ and $3 D(\mathbf{O}, \mathbf{P})$ microenvironments by immunoreactivity to $\beta$-tub/II (M,O) and tyrosine hydroxilase (N,P). Cell nuclei were stained with DAPI (Blue). (Magnification A-L, M, O: 400x; N,P: 640x).

coated with Matrigel ${ }^{\mathrm{TM}}$ lot I and around $70 \%$ of wells coated with Matrigel $^{\mathrm{TM}}$ lot II contained cartilage nodules (Fig. 3). The frequency of wells coated with Matrigel ${ }^{\mathrm{TM}}$ lot III containing cartilage nodules was around $50 \%$. When Matrigel ${ }^{\mathrm{TM}}$ lots were combined, as I+II+III, glial cells, neurons, melanocytes and smooth muscle cells were found in $80-100 \%$ of wells, whereas chondrocytes were observed in $66 \%$ of them (Fig. 3, black bars).

Glial cells, melanocytes and smooth muscle cells mostly developed in large and dense populations (Fig. 2 E-F, I-J), making it difficult to individually quantify these phenotypes. For that reason, the amount of each phenotype per well was estimated, and we observed similar magnitudes of these phenotypes in all the analyzed conditions (Table 1).

TABLE 1

ESTIMATED AMOUNT OF MELANOCYTES, GLIAL CELLS AND SMOOTH MUSCLE CELLS PER WELL IN TNCCS CULTURED ON MATRIGEL ${ }^{\text {TM }}$

\begin{tabular}{lcccc} 
& Lot I & Lot II & Lot III & Lots I+II+III \\
\hline Melanocytes & +++ & +++ & +++ & ++ \\
Glial cells & ++++ & +++ & +++ & +++ \\
SMA & +++ & +++ & +++ & +++ \\
\hline
\end{tabular}

Four main groups classified according to the estimated quantity of each phenotype: small $(+)$, medium (++), great $(+++)$ and very great amount $(++++)$.

\section{Matrigel $^{T M}$ lots in combination influence the amount of cartilage nodules in TNCCs cultures}

Cartilage nodules and neurons occurred in clusters or as a few individual cells, respectively (Fig. $2 \mathrm{C}$ and $2 \mathrm{M}$ ). Accordingly, the number of nodules or individual neuronal cells per well was easily quantified (Fig. 4). No differences in these cell phenotypes were observed among the three lots of Matrigel ${ }^{\mathrm{TM}}$ when lots were analyzed separately. However, a reduction of 1.8-fold in relation to separate lot I was observed in the number of cartilage nodules when the combination of Matrigel ${ }^{\mathrm{TM}}$ lots was used. Similarly, no significant differences in the number of neurons were observed among the different separate lots, but a slight increase of neuronal cells was detected in the combined lot assay (Fig. 4).

\section{Discussion}

In this paper, we propose a new method of in vitro culture to study NC cells using Matrige ${ }^{\mathrm{TM}}$ as a substrate to support the main repertoire of NCCs differentiation. Although previous studies reported differentiation of NC-derived cell types, such as neurons and melanocytes, on basement matrix membranes (Griffith and Sanders 1991; Maxwell and Forbes 1987), the differentiation of both "neural" and "mesenchymal" phenotypes on Matrigel ${ }^{\mathrm{TM}}$ has never been addressed. Variations in different Matrigel ${ }^{\mathrm{TM}}$ lots have been suggested as the major inconvenience limiting its use (Bigdeli et 


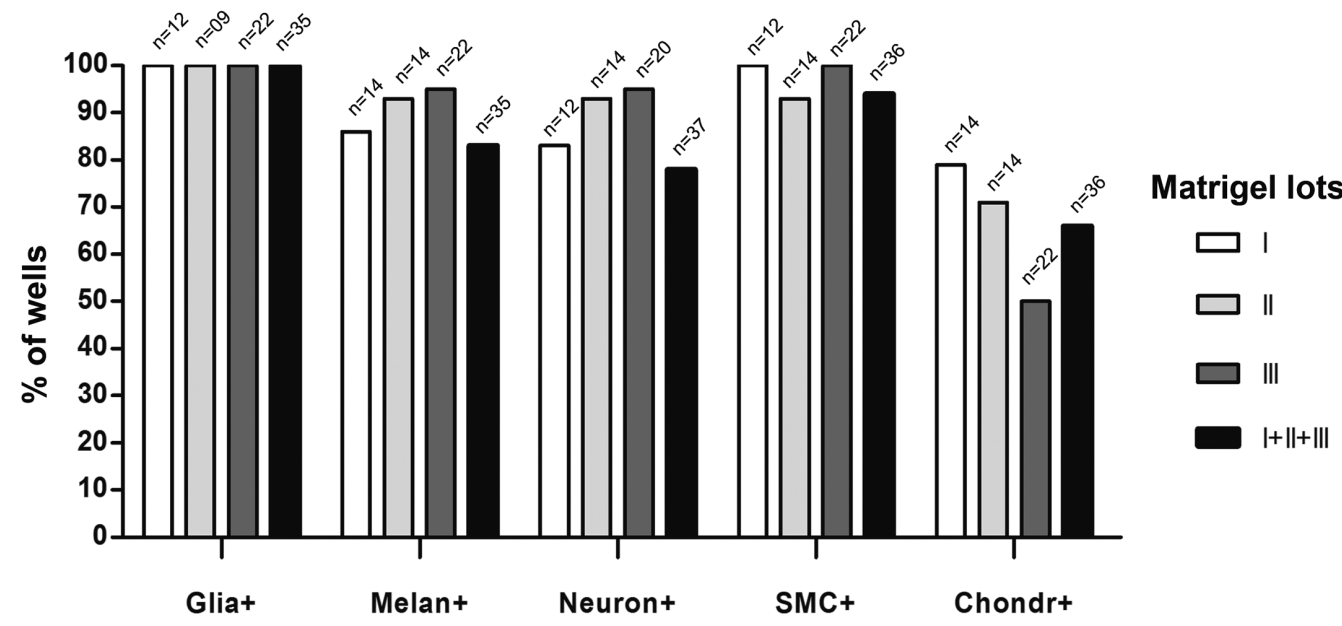

Fig. 3. Matrige $\mathrm{l}^{\mathrm{TM}}$ lots are equivalent in supporting TNCC differentiation to glial, melanocyte and smooth muscle cell types. Frequency of wells containing glial cells, melanocytes, neurons, smooth muscle cells and cartilage nodules in $10 d$ cultures of TNCCs grown on separate Matrige/TM lots, i.e, lots I, II and III, or in combination, i.e., lots $1+11+I I I$ (see Materials and Methods), expressed as mean \% of the total number of wells containing each phenotype ( $n$, above each column). Data obtained from 2 independent experiments where $P<0.05$ by $\chi^{2}$ test in all analysis. al., 2008). However, in our study, all the analyzed lots of Matrigel ${ }^{\mathrm{TM}}$ were efficient in promoting NCC differentiation, resulting in similar frequencies of NC-derived phenotypes. Nevertheless, when we compared the frequency of cartilage nodules by lot, we observed that wells containing lot III had fewer cartilage nodules by about $25 \%$ than wells containing lots I and II. This finding could be important in NC studies since this phenotype is hard to obtain. Notwithstanding this finding, the high frequency of wells containing cartilage nodules is striking when compared with our previous report (Calloni et al., 2007). McGonnell and Graham (2002) demonstrated, for the first time, the skeletogenic potential of TNC cultures performed on a 2D plastic surface (McGonnell and Graham 2002). Five years later, our group confirmed these data. Specifically, we cultured TNCCs (800 NCCs plated per well) on 3T3 feeder layers, resulting in $16 \%$ of wells containing chondrocytes (Calloni et al., 2007). This frequency rose to $43 \%$ after stimulation by the morphogen Sonic Hedgehog (Shh) (Calloni et al., 2007). Notably, in the present study, using the 3D Matrigel ${ }^{\mathrm{TM}}$ microenvironment, even the least effective lot III generated more cartilage nodules (>50\% of wells) than the best 2D TNC culture condition, i.e., 43\% in 3T3 fibroblast feeder layers + Shh. Remarkably, in the present work, we plated only 200 NCCs/well. Nevertheless, the mean number of cartilage

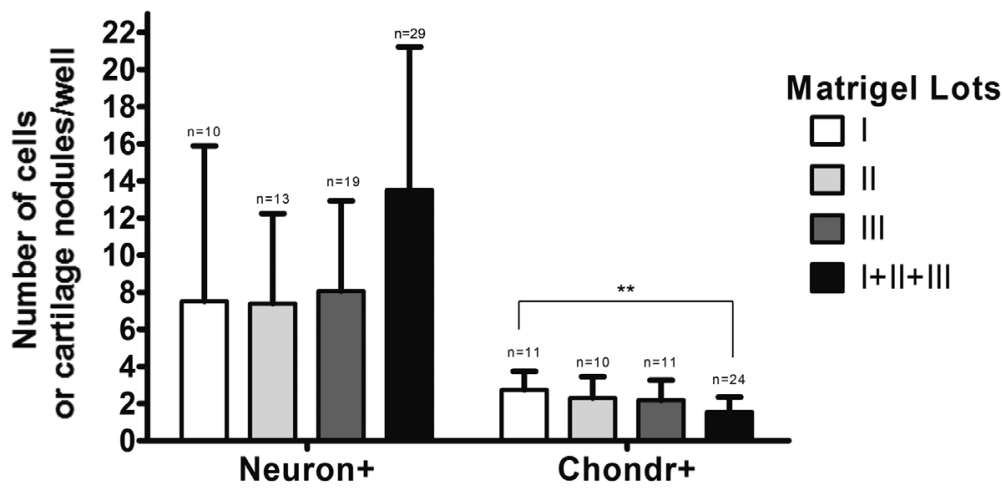

Fig. 4. Combined Matrigel ${ }^{\mathrm{TM}}$ lots influence the generation of cartilage nodules. The number of neurons and cartilage nodules per well was quantified at 10d of TNCC cultures. Data are shown as mean $( \pm$ SEM) for each phenotype in the three separate Matrige ITM lots, i.e., I, II and III, or in combination, i.e., I+II+III. Data obtained from 2 independent experiments. The number of wells analyzed is shown above the bars. ** $P<0.01$ by One-way ANOVA with Bonferroni's post-test. nodules per well did not change compared to our previous work (Calloni et al., 2007).

Whereas Matrige $\mathrm{I}^{\mathrm{TM}} \mathrm{I}+\mathrm{II}+\mathrm{III}$ normalized the number of chondrocytes, it reduced the number of cartilage nodules per well and promoted a slight increase of neuronal cells per well. Synergism between growth factors and/or extracellular matrix molecules of Matrigel ${ }^{\mathrm{TM}}$ could explain these data. Apart from this result, differences in Matrigel ${ }^{\mathrm{TM}}$ lots did not significantly alter NC cell differentiation, indicating that the combination of Matrigel ${ }^{\mathrm{TM}}$ lots, i.e., I+II+III, promotes chondrocyte differentiation. Indeed, Matrige ${ }^{\mathrm{TM}}$ would be useful for single-cell cultures of NC, especially for subcloning experiments.

Since Matrigel ${ }^{\mathrm{TM}}$ is a very complex mixture of growth factors and extracellular matrix molecules, it is difficult to address the specific molecule(s) responsible for inducing the high rate of chondrogenesis observed here (Fig. 3). Indeed, around $60 \%$ of the protein content of Matrigel ${ }^{\mathrm{TM}}$ corresponds to laminin (Kleinman et al., 1986). However, laminin is not the primary chondrogenic agent in Matrigel ${ }^{\mathrm{TM}}$ in limb bud cultures (Bradham et al., 1995). Moreover, neutralizing antibodies to TGF $\beta$ and FGF, the classic inducers of chondrocytic differentiation also present in Matrigel ${ }^{\mathrm{TM}}$, did not affect the rate of limb bud chondrogenesis (Bradham et al., 1995). Therefore, future studies must be performed to address this open question.

Another possibility is that the simple 3D microenvironment could stimulate NC cells to adopt a chondrogenic phenotype. Nowadays, it is becoming clear that simple variations in texture or malleability of the substrate can dramatically influence stem cell lineage choice (Discher etal., 2009). Both previous and recent studies demonstrate that the physical properties of substrates are able to influence cell morphology which, in turn, changes gene expression and determines cell fate (for review see Baker and Chen 2012; Daniels and Solursh 1991; Lutolf et al., 2009). Moreover, embryonic and mesenchymal stem cells plated in non adhesive 3D or high density microenvironments maintain the round shape of their nuclei, which promotes their differentiation into chondrocytes (McBride and Knothe Tate 2008). Our data corroborate these findings since cartilage nodules were detected almost exclusively in the 3D Matrige ${ }^{\mathrm{TM}}$ microenvironment, where chondrocytes did, indeed, display a round shape (Fig. 2C-D). On the other hand, the rare cartilage nodules observed in 
the 2D Matrigel ${ }^{\mathrm{TM}}$ microenvironment contained irregular shaped chondrocytes, less round and even flat (Fig. 2 A-B). In sum, these findings point to the importance of 3D microenvironment to stimulate chondrogenesis from undifferentiated TNCCs.

Finally, Matrigel ${ }^{\mathrm{TM}}$ might also promote the appearance of neurons, since they were observed in high frequency and numbers in our experiments. Basement membrane matrix was shown to increase the number of adrenergic neurons in TNCC cultures of quail (Forbes et al., 1993; Maxwell and Forbes 1987). Our data corroborates these studies, since we detected more adrenergic neurons in the 3D microenvironment. We also observed that neuronal cells more frequently co-express beta-tubulin III with HNK1 in the 3D microenvironment. Thus, our results suggest that Matrigel $\mathrm{I}^{\mathrm{TM}}$ corresponds to an improved microenvironment that supports the main repertoire of NC potentiality, representing an alternative to the 2D mouse fibroblast 3T3 feeder layers in studies involving NC multipotentiality and, possibly, self-renewal.

\section{Materials and Methods}

\section{Cell cultures}

\section{Primary cultures}

Trunk neural crest cells (TNCCs) were isolated from explanted neural tubes dissected at thoracic level (last 10 somites) from quail embryos at 20-25 somite stage. Briefly, the explanted neural tubes were plated on a 35 $\mathrm{mm}$ plastic dish (Corning ${ }^{\circledR}$ ) with $\alpha$-modified minimum essential medium $(\alpha$ MEM, Invitrogen ${ }^{\circledR}$ ) enriched with $10 \%$ FBS (fetal bovine serum, Vitrocell囚) and $2 \%$ chicken embryo extract. After 15 hours of primary culture, neural tubes were discarded with tungsten needles, and the remaining migrating NC cells were harvested with the enzyme trypsin $\left(0.05 \%\right.$, Sigma $\left.{ }^{\circledR}\right)$ to perform secondary cultures.

\section{Secondary cultures}

Isolated TNCCs (around 200 cells/well) were plated on the surface of basement membrane matrix (herein known as Matrigel ${ }^{\mathrm{TM}}$ ) - previously coated culture dishes. Briefly, previously cooled $\left(-20^{\circ} \mathrm{C}\right) 96$-well culture plates were covered with $20 \mu \mathrm{l}$ Matrigel $^{\mathrm{TM}}$ (BD Biosciences). Using this procedure, two distinct microenvironments were created in each well: 1) a thin Matrige ${ }^{\mathrm{TM}}$ layer in the well's center to mimic a conventional 2D substrate and 2) a $0.1 \mathrm{~mm}$ thick Matrigel ${ }^{\mathrm{TM}}$ layer to mimic a 3D microenvironment, which formed at the border of the well (Fig. 1).

Three separate lots of Matrigel ${ }^{\mathrm{TM}}$ (I, II and III) or lots combined in equivalent proportions $(I+I+I I I)$ were evaluated. The cultures were maintained for 10 days in the culture medium described for primary cultures, at $37^{\circ} \mathrm{C}$ in a humidified $5 \% \mathrm{CO} 2 / 95 \%$ air atmosphere with medium replacement every 3 days.

\section{Phenotypic analysis}

After 10 days of secondary culture, TNCCs were fixed with 4\% paraformaldehyde and analyzed by immunofluorescence using lineage-specific markers as previously described (Calloni et al., 2007). Briefly, pigment cells were recognized by the presence of melanin. Smooth muscle cells were identified by immunostaining with $\alpha$-smooth muscle actin ( $\alpha$-SMA) monoclonal antibody (Mab) (Sigma $\left.{ }^{\circledR}\right)$. Neurons and adrenergic cells were observed respectively, by immunostaining with beta III-Tubulin ( $\beta$ III-Tub) (Promega ${ }^{\circledR}$ ) and Tyrosine Hydroxilase Mabs (TH - undiluted hybridoma supernatant). Cartilage was detected by phase-contrast microscopy and by immunostaining with $\alpha$-Chondroitin Sulfate Mab (Sigma $\left.{ }^{\circledR}\right)$. Glial cells were identified by immunostaining with Schwann Myelin Protein (SMP) and Human Natural Killer 1 (HNK1) Mabs (both undiluted hybridoma supernatants). Secondary antibodies were obtained from Southern Biotechnology Associates. Cell nuclei were stained with 4',6-Diamidino-2-Phenylindole,
Dihydrochloride (DAPI; Sigma®). Fluorescence labeling was observed using an epifluorescent microscope (Olympus IX71).

\section{Statistical analysis}

Frequencies of wells with a given phenotype were analyzed by $\chi^{2}$ test and considered significant when $\mathrm{P}<0.05$ with the Bonferroni's post-test. Cell numbers were analyzed by One-way ANOVA and considered significant when $\mathrm{P}<0.05$.

\section{Acknowledgements}

This work was supported by the Ministério da Ciência e Tecnologia/ Conselho Nacional de Desenvolvimento Científico e Tecnológico (MCT/ CNPq/Brazil), MCT/INFRA (Brazil), PRONEX/CNPq, Coordenação de Aperfeiçoamento de Pessoal de Nível Superior (CAPES, Brazil), Instituto Nacional de Neurociência Translacional (INNT) and Fundação de Amparo de Pesquisa do Estado de Santa Catarina (FAPESC, SC, Brazil). Both Ana Belén Ramos Hryband Meline Coelho da Costa received a fellowship from CAPES.

\section{References}

BAKER BM, CHEN CS (2012). Deconstructing the third dimension - how 3D culture microenvironments alter cellular cues. J Cell Sci 125: 3015-3024.

BIGDELIN, ANDERSSON M, STREHLR, EMANUELSSONK, KILMARE E, HYLLNER J, LINDAHLA (2008). Adaptation of human embryonic stem cells to feeder-free and matrix-free culture conditions directly on plastic surfaces. JBiotechnol 133: 146-153.

BILOZUR ME, HAY ED (1988). Neural crest migration in 3D extracellular matrix utilizes laminin, fibronectin, or collagen. Dev Biol 125: 19-33.

BIRGERSDOTTER A, SANDBERG R, ERNBERG I (2005). Gene expression perturbation in vitro--a growing case for three-dimensional (3D) culture systems. Seminar Cancer Biol 15: 405-412.

BITTENCOURTDA, DACOSTAMC, CALLONI GW, ALVAREZ-SILVAM, TRENTINAG (2013). Fibroblast Growth Factor 2 Promotes the Self-Renewal of Bipotent Glial Smooth Muscle Neural Crest Progenitors. Stem Cells and Develop22:1241-1251.

BRADHAM DM, PASSANITI A, HORTON WEJR (1995). Mesenchymal Cell Chondrogenesis is stimulated by basement membrane matrix and inhibited by ageassociated factors. Matrix Biol 14: 561-571.

CALLONI GW, GLAVIEUX-PARDANAUD C, LE DOUARIN NM, DUPIN E (2007). Sonic Hedgehog promotes the development of multipotent neural crest progenitors endowed with both mesenchymal and neural potentials. Proc Natl Acad Sci USA 104: 19879-19884.

COSTA-SILVA B, DA COSTA MC, MELO FR, NEVES CM, ALVAREZ-SILVA M, CALLONI, GW, TRENTIN AG (2009). Fibronectin promotes differentiation of neural crest progenitors endowed with smooth muscle cell potential. Exp Cell Res 315: 955-967.

DANIELSK, SOLURSH M (1991). Modulation of chondrogenesis by the cytoskeleton and extracellular matrix. J Cell Sci 100: 249-254.

DISCHER DE, MOONEY DJ, ZANDSTRA PW (2009). Growth factors, matrices, and forces combine and control stem cells. Science 324: 1673-1677.

FORBES ME, CURTIS ML, MAXWELL GD (1993). Temporal restriction of neural crest development in vitro: changes in the adrenergic differentiation of neural crest clusters in the presence and absence of an overlay of reconstituted basement membrane-like matrix. Exp Neurol 120: 114-122.

GRIFFITH CM, SANDERS EJ (1991). Effects of extracellular matrix components on the differentiation of chick embryo tail bud mesenchyme in culture. Differentiation 47: 61-68.

ITO K, MORITA T, SIEBER-BLUM M (1993). In vitro clonal analysis of mouse neural crest development. Dev Biol 157: 517-525.

KLEINMAN HK, MARTIN GR (2005). Matrigel: basement membrane matrix with biological activity. Semin Cancer Biol 15: 378-386.

KLEINMAN HK, MCGARVEY ML, HASSELL JR, STAR VL, CANNON FB, LAURIE GW, MARTIN GR (1986). Basement membrane complexes with biological activity. Biochemistry 25: 312-318.

LE DOUARIN N, KALCHEIM C (Ed. $\left.2^{\text {nd }}\right)$ (1999). The Neural Crest. Cambridge University Press, United Kindom. 
LUTOLF MP, GILBERT PM, BLAU HM (2009). Designing materials to direct stem-cell fate. Nature 462: 433-441.

MAXWELL GD, FORBES ME (1987). Exogenous basement-membrane-like matrix stimulates adrenergic development in avian neural crest cultures. Development 101: 767-776
MCBRIDE SH, KNOTHE TATE ML (2008). Modulation of stem cell shape and fate A the role of density and seeding protocol on nucleus shape and gene expression. Tissue Eng Part A 14: 1561-1572.

MCGONNELL IM, GRAHAM A (2002). Trunk neural crest has skeletogenic potential. Curr Biol 12: 767-771.

\section{Further Related Reading, published previously in the Int. J. Dev. Biol.}

Alcohol promotes in vitro chondrogenesis in embryonic facial mesenchyme.

L M Hoffman and W M Kulyk

Int. J. Dev. Biol. (1999) 43: 167-174

http://www.intjdevbiol.com/web/paper/10235393

Culture on basement membrane does not reverse the phenotype of lens derived mesenchyme-like cells.

A Zuk, H K Kleinman and E D Hay

Int. J. Dev. Biol. (1989) 33: 487-490

http://www.intjdevbiol.com/web/paper/2641354

Chondrogenesis of mandibular mesenchyme from the embryonic chick is inhibited by mandibular epithelium and by epidermal growth factor.

$\mathrm{P}$ A Coffin-Collins and B K Hall

Int. J. Dev. Biol. (1989) 33: 297-311

http://www.intjdevbiol.com/web/paper/2641350

Effects of growth factors on the differentiation of neural crest cells and neural crest cell-derivatives.

B K Hall and S Ekanayake

Int. J. Dev. Biol. (1991) 35: 367-387

http://www.intjdevbiol.com/web/paper/1801864

Collagen I, laminin, and tenascin: ultrastructure and correlation with avian neural crest formation.

R A McCarthy and E D Hay

Int. J. Dev. Biol. (1991) 35: 437-452

http://www.intjdevbiol.com/web/paper/1724907

5 yr ISI Impact Factor $(2011)=2.959$
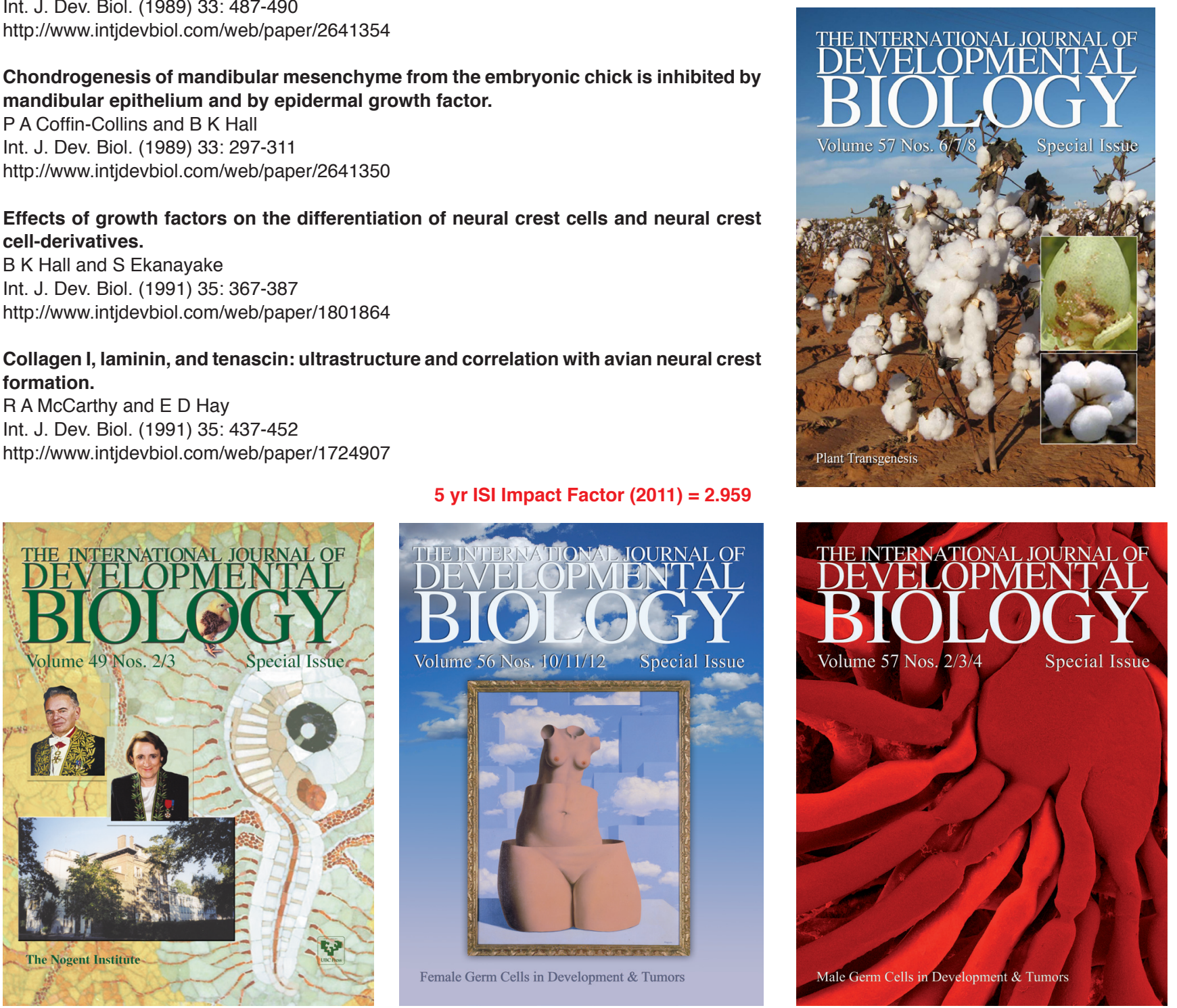